\title{
Electric Power Application to Passenger and Freight Elevators
}

\author{
BY HARRISON P. REED \\ Fellow, A. I. E. E. \\ Cutler-Hammer Manufacturing Co., Milwaukee, Wis.
}

(Concluded from page 67 of the January Journal)

\section{IV-ELEVATOR CONTROLLERS}

$\mathrm{T}^{\mathrm{T}}$

EE elevator controller is one of the most important and at the same time perhaps the most complicated part of the equipment as it provides many of the safety features. The smooth operation of the elevator car is largely dependent upon its functioning, and the design affects the power consumption to a marked degree. Considerable economy can be obtained by selecting the best type for each particular application.

\section{CharaCteristics}

Among the more important characteristics of the control are safety and reliability, although the motor selected should have characteristics that render it inherently safe for elevator operation. The connections to the controller must permit stopping the car at any time under any conditions of load; it should automatically stop upon the release of the car switch handle by the operator. The elevator car must be stopped automatically at each limit of travel to prevent it from traveling into the pit at the bottom or sheave beams at the top of the hoistway. The question of safety is associated with that of reliability. Even if the scheme of control is essentially safe, its proper functioning depends upon the apparatus being reliable.

Controllers must be designed and built to withstand frequent severe operation; one half a million operations a year, partly at least with inexperienced operators who do a great deal of "inching" for landings, not being unusual. Frequent plugging is common, with resultant high currents to be commutated. Also the location of elevator machinery is not conducive to regular inspection, and frequently maintenance is left to the janitor of a building who ordinarily knows little about electrical apparatus and its care.

Elevators are installed in buildings for the purpose of carrying passengers between the ground floor and the upper floors. Many buildings are so tall that it would be a distinct hardship and often an impossibility for the tenants to walk up and down stairs. It is, therefore, necessary to have the elevators in operating condition at all times. In the event of fire or accident it is important that they should function properly to remove the tenants from the upper floors of the building.

Frequently the elevator equipment is located above the hoistway or adjacent to it, so that it is essential to have the controller quiet; otherwise it may disturb the persons who occupy the upper floors.
All unnecessary complications should be eliminated from the controller and all essential adjustments should be readily understood and easily made. After being adjusted the parts should remain fixed under normal operating conditions.

The controller should be neat in appearance and all working parts readily accessible for inspection and repairs. It should be so located as to provide ample working space around it, and sufficient illumination should be provided to facilitate inspecting and repairing this apparatus.

\section{FUNCTIONS}

The elevator controller performs a number of different functions, among the most important of which are the following:

To start the motor and accelerate it to full speed in either the up or the down direction, and to stop it at the will of the operator.

The starting and the stopping of the motor is performed by switches which must make and break the electric circuit. These switches are subject to considerable burning and should be of such design as to withstand this action with infrequent repairs and renewal of parts. The smooth acceleration and re. tardation of the motor are most important, and usually present the greatest difficulties in the design of the controller. Under different conditions of loading, the motor may act either as a motor or as a generator; therefore the usual methods of accelerating and retarding with a positive load may not give smooth operation when the load is negative. For example; when resistance is inserted in the armature circuit of a d-c. motor under a positive load, the speed of the motor decreases in proportion to the resistance which is inserted. If, on the other hand the motor has a negative load and is operating as a generator, the more resistance inserted in the armature circuit, the faster will be the motor speed. It can be readily seen, therefore, that the ordinary methods of control are not suitable for elevator service. The same remarks apply to a slip-ring induction motor with resistors in the secondary circuit.

To control the speed of the motor at the will of the operator.

The various methods of speed control will be discussed under a separate heading. It is necessary for the control to provide for one or more reduced operating speeds in order to make a satisfactory landing, particularly where the car speed is high. These low speeds should be positive so that they are available 
when the motor is operating as a generator as well as under positive load.

To stop the elevator at each limit of travel.

The elevator car travels in a hoistway which is limited at the bottom by a pit and at the top by the beams which support the sheaves and often the winding machinery.

Low-speed elevators can be readily stopped at the top and bottom landings without a preliminary slowdown device, but the higher-speed passenger elevators must be slowed down before the terminal landings are reached in order to make a successful stop. This can be better understood if we consider that the car may be approaching the bottom landing in one case with no-load and in the other case with the maximum load. If the car operates at a speed of 400 or $500 \mathrm{ft}$. per min. the loaded car will drift considerably farther than the empty car when the controller disconnects the motor from the line and applies the brake. The terminal stops must be so adjusted that the car will reach the bottom landing with a light load. It will, therefore, drift considerably beyond this landing with the maximum load. If the controller provides means for reducing the speed of the car to 50 or $100 \mathrm{ft}$. per min. before the final stop is made the difference in drift between no-load and full-load will be very small and a satisfactory stop can be made.

To provide additional means for disconnecting the motor from the line and applying the brake in case of overtravel.

The car is stopped at either limit of travel by the regular slow-down and stopping device, but should this device become inoperative, additional means are provided for positively disconnecting the motor from the line and applying the brake in case the car travels beyond its ordinary limits. This latter means usually consists of hoistway limit switches so arranged that the car will open them and stop if it travels beyond its usual limits.

To provide a brake which will positively stop the car and hold it securely at the landing.

Two forms of brakes are used. One is a mechanical brake which is applied by a spring and released by a magnet. This brake is set when the magnet coil is disconnected; it is used for making the final stop and holding the load. The other is the dynamic brake which is used on direct-current machines to assist the magnet brake in stopping the machine. This is obtained by connecting the terminals of a d-c. motor to a resistor, the moving load driving the motor as a generator. By changing the resistance in the armature circuit the retarding torque can be adjusted to suit existing conditions. The satisfactory stopping of the car depends upon the proper adjustment of these two methods of braking.

The controller should govern the motor in an economical manner. The degree of economy will differ for each type of equipment. The current which passes through the resistor units represents a direct loss of energy; therefore the longer this resistance is in circuit, and the more current that passes through it, the less the efficiency of the elevator.

\section{Methods OF OpERATION}

A controller may be operated in several ways:

Hand Rope and Lever Control. This consists of a rope which runs the full length of the hoistway in the form of a loop. (Fig. 7 shows the electrical equipment). One half of this loop passes through the elevator car. While the car is in operation this rope is stationary. In order to start, the operator pulls on the rope. This moves the controller and connects the motor to the line for the proper direction of rotation. When the

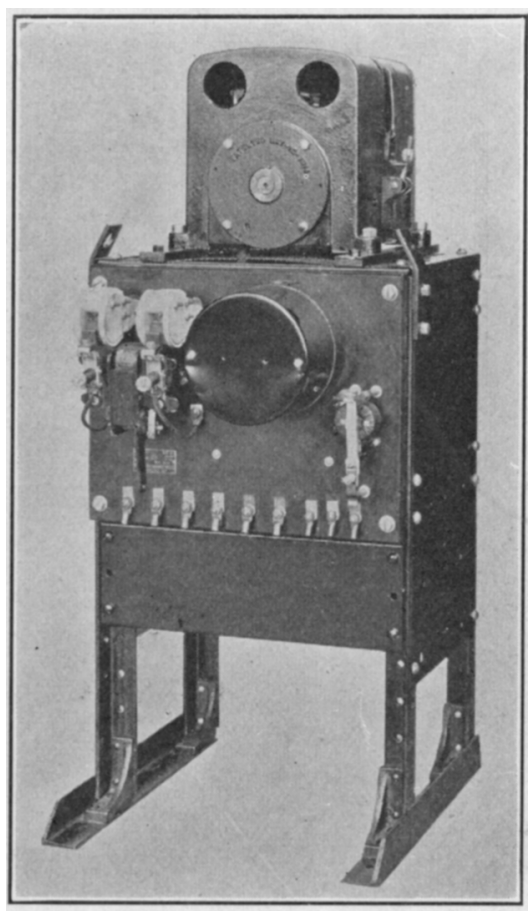

Fig. 7-Self-Contained A-C. Semi-Magnet Elevator Controller

With phase failure, phase reversal and low-voltage protection

desired landing is reached the operator takes hold of the rope so that the movement of the car pulls the rope in the opposite direction and brings the car to rest. This method of operating elevators is used for low-speed freight machines. A lever or hand-wheel may be used for manipulating this rope instead of having the operator pull on the rope directly. Attachments of this kind enable the operator to govern the controller at higher car speeds, but they are rather cumbersome and not as desirable as full electric control.

Car Switch Control. This method consists of locating a master switch in the car. (Figs. 8 and 9 show typical control panels.) The movement of the master switch handle to either side causes the car to travel in the direction desired. The connections are usually made so that the movement of the handle toward the door or front of the car causes a downward motion and a 
movement in the reverse direction an upward motion. The switch is arranged with a spring for centering the handle in case the operator releases it, thus bringing the car to rest. The handle is provided with a latch for holding it firmly in the "off" position to prevent accidental starting of the car.

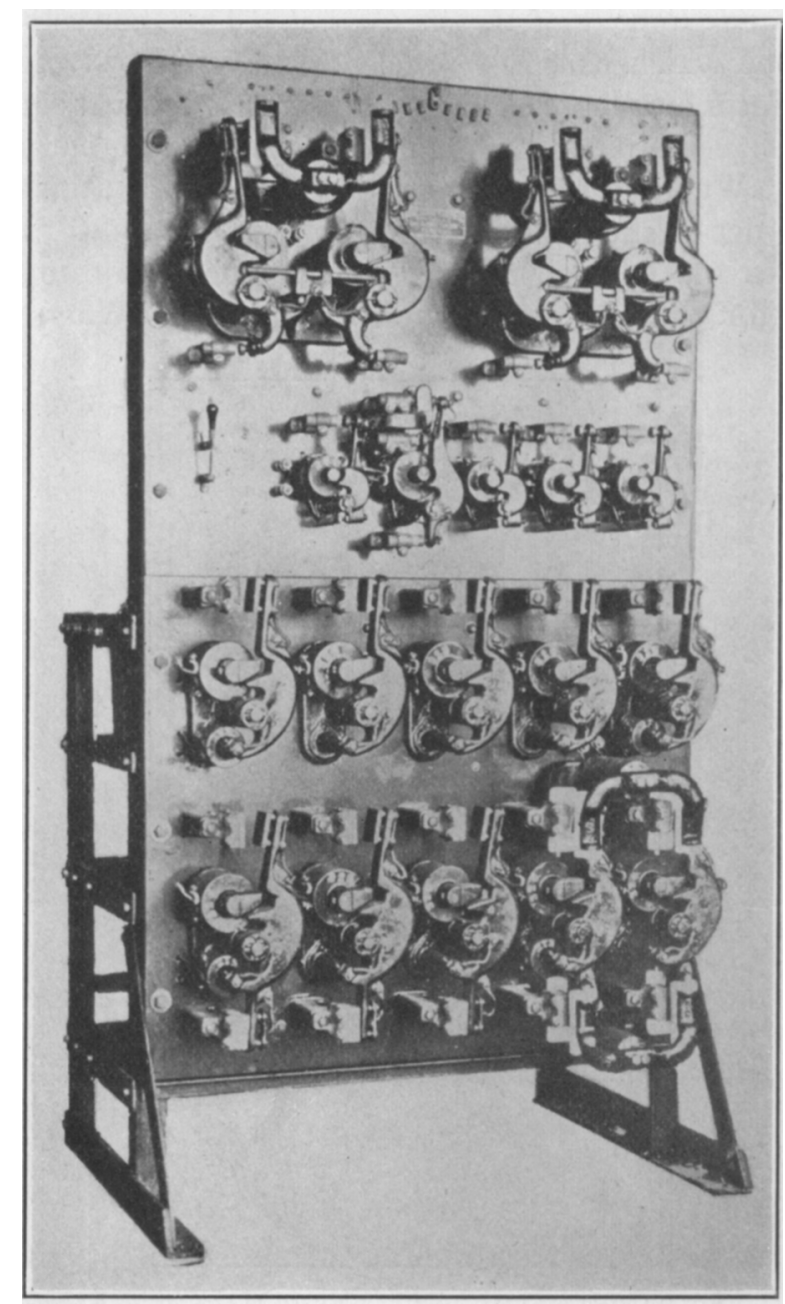

Fig. 8-Full-Magnet D-C. Elevator Controller

This master switch is connected by wires with contactors on the control panel and operates the elevator by energizing the magnets of these contactors. The acceleration of the car is automatic so that the car switch is used only to determine the direction of travel and to select the proper operating speed.

Push Button Control. This method of controlling the car provides for automatically stopping it at the desired landing. (Fig. 10 shows a typical control panel.) It has a particular field of application in apartment houses, small hotels, stores, clubs, etc. where the service does not warrant the expense of a regular operator. The control itself is inherently more complicated than other types and therefore is not quite as reliable. It is a time and power waster because so many trips are made with light loads and without regard to floor demands.

A push button is located near each landing door.
When a button is depressed momentarily, the proper connections are set up in the controller to move the car to that particular landing and to automatically stop it when it reaches the landing. Inside the car is located a series of buttons, one button corresponding to each landing. When the passenger enters the car and closes the landing door and car gate he momentarily presses the button corresponding to the desired landing. The car then travels to that landing and automatically stops. The control for elevators of this kind is substantially the same as for an elevator using a car switch, with the addition that a selector switch is provided which is driven either by the machine or by the elevator car and makes the connections that automatically stop the car at the desired landing. One form of selector is shown in Fig. 11.

Dual Control. Dual, or combination, car switch and push button control fills a demand where the service justifies the employment of an operator for only part of the time that the elevator must be in service. This demand comes in larger apartment houses, industrial office buildings, clubs, etc. Its first cost is higher than that of any other type, but due to the two different

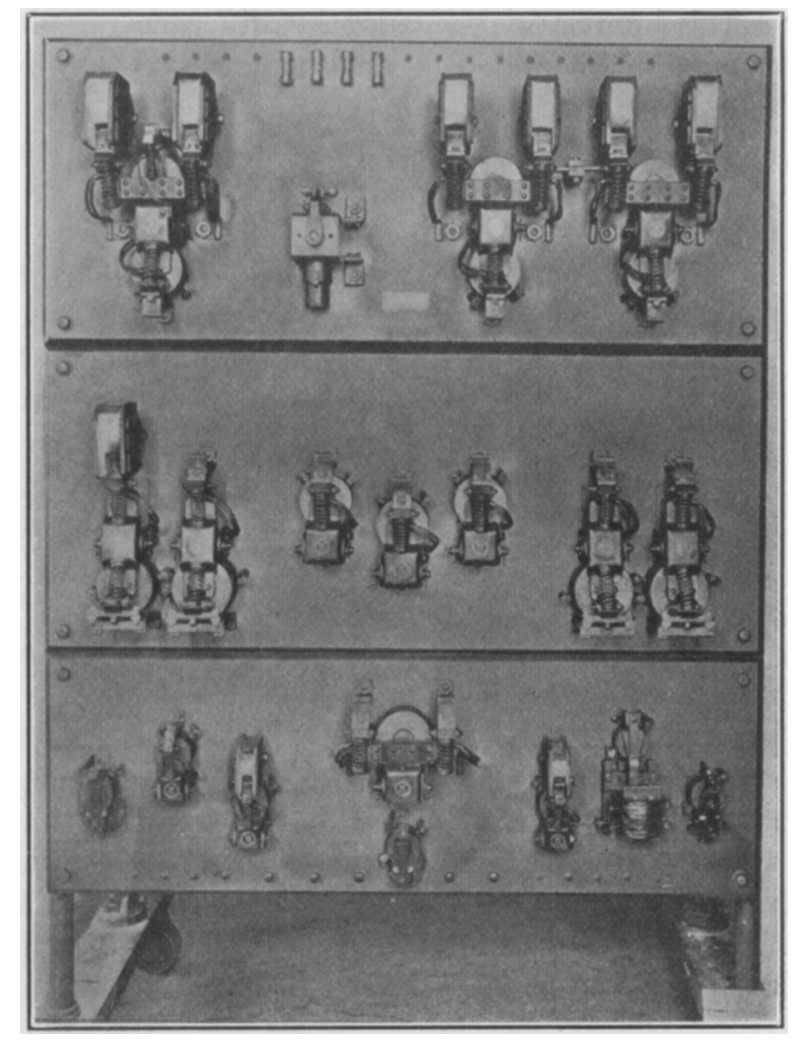

Fig. 9-D-C. Gearless Traction Elevator Controller

forms of control is somewhat more reliable than the straight push button control. Push buttons are provided at each landing for calling the car to that landing. A set of push buttons and a master switch is placed inside the car. Means are provided to render the push buttons within the car inoperative when the car switch is being used. At the same time the connections to 
the landing push buttons are transferred to the annunciator operation.

\section{Method OF ACCELERATION}

The elevator motor is automatically accelerated from rest to the operating speed. There are several methods for obtaining this automatic acceleration. Among the more common methods are the following:

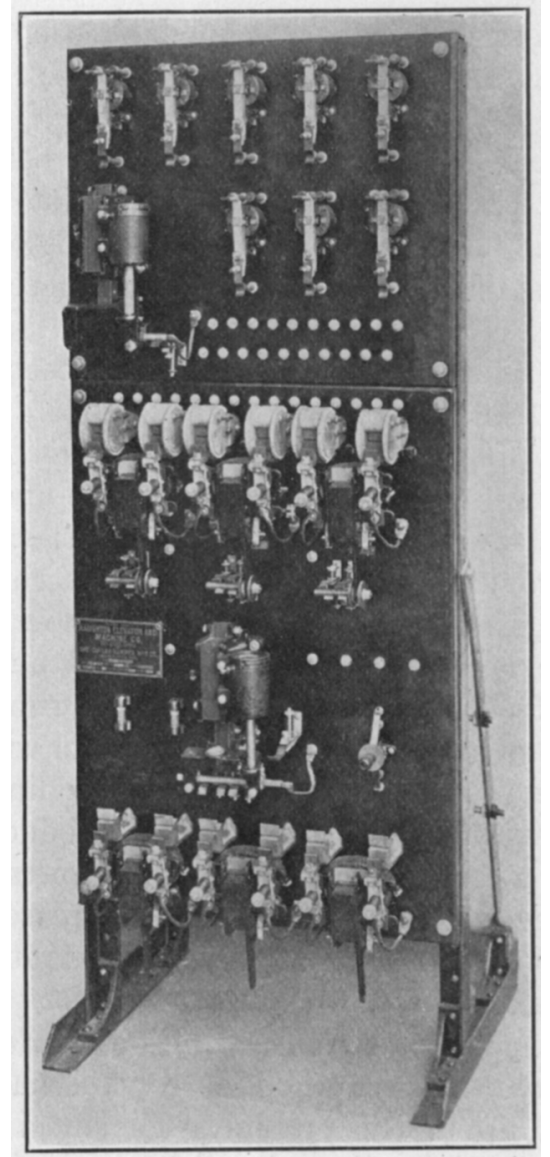

Fig. 10-A-C. Full-Magnet Elevator Controller With floor selector relays for push-button operation.

Time Element Acceleration. This is based on the principle that time is required to accelerate the motor. Usually the device provides a definite time for acceleration independent of the load of the car. One of the most common devices of this type is a dash-pot, either air or oil.

The advantage of this method of acceleration is the smooth start which it provides under all conditions of loading. Sufficient resistance can be provided to start the car smoothly with a light load. With a heavy load the timing device short-circuits sections of resistance until the motor develops sufficient torque to accelerate the load. Well designed accelerators of this type are not materially affected by variations in line voltage.

Counter E.M.F. Acceleration. This method makes use of the principle that the voltage across the terminals of the elevator motor increases with the speed of the motor so that magnet contactors connected across these terminals have their magnetism increased with the speed of the motor and can be adjusted to short-circuit sections of the starting resistance corresponding to different motor speeds. These magnetic contactors when properly designed are not affected seriously by atmospheric conditions, dust, or dirt, and therefore should remain in adjustment. This method of acceleration is sensitive to a variation in line voltage, but elevators are usually connected to the same service lines that furnish the lighting for the building and the voltage regulation is generally very good. Where poor regulation exists, special devices can be used to compensate for voltage fluctuation. The starting resistor should permit the motor to develop sufficient torque to start the maximum load.

Current-Limit Acceleration. This method of acceleration is dependent upon the current taken by the motor during acceleration. The motor must draw sufficient inrush current from the line to develop the torque necessary to start hoisting the maximum load. After this load has been started from rest the friction decreases as the running friction is less than the static friction; therefore, a larger part of the motor torque is available to accelerate the load, and the motor increases in speed until the torque developed is just sufficient to balance the load. At this value of current a relay closes the contacts to the next accelerating switch which in turn accelerates the motor to a higher balance speed. This process is repeated until all of the starting resistance has been short-circuited. With this method of control the motoi' is accelerated at a constant torque value, and therefore it reaches full speed quicker with a light load than with a heavy load as more torque is available for acceleration.

All magnetic contactors require an appreciable time to close so that any control system using contactors will have some time element. By modifying the design of these contactors the time element can be

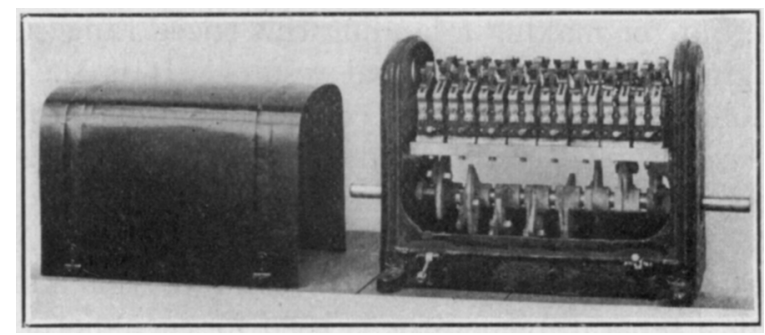

Fig. 11-Elevator Floor Selector

increased. This small time element is useful when the counter e. m. f. or current-limit method of acceleration is used to assist in giving a smooth start.

Another element which contributes towards smooth operation is the induction in the motor circuit. This inductive action checks the rush of current at the time a contactor short-circuits a section of armature resisttance. The inductive effect may be increased by 
adding an impedance coil to the circuit or by a special design of the elevator motor itself. The time constant of the motor may be increased by several well known methods, thus smoothing out the transition between the steps in the controller.

An elevator motor may be accelerated by a combination of two or more of these methods. As pointed out above, there is always some time element in every contactor, which may be increased by special design, this giving a combination of time element acceleration with either counter e.m.f. or current-limit acceleration.

V. Methods of Speed Control. The speed control of the elevator motor is very closely associated with the method of acceleration and may assist materially in smoothing out this acceleration. The method of speed control depends upon the type and design of motor. Some of the methods are as follows:

By Adjusting the Field Strength of the D-C. Motor. Most direct-current motors can be operated at different speeds by simply changing the strength of their fields. The range of speed obtained depends upon the design of the motor. If a considerable change in speed is required by this method, a larger and more expensive motor is required than for the ordinary constant-speed design. If the motor is massive and responds slowly to a change in field strength, very little difficulty is introduced by this method of speed control. If, however, the motor responds quickly, relays or other devices are used to limit the current during the change in speed. This method of speed control is very popular, particularly for the higher-speed, geared elevators. This is a very economical method of speed control.

By Connecting Resistors in Series and in Shunt with a D-C. Motor Armature. The shunt resistor has a stabilizing influence and limits the speed variation under different conditions of loading. This method of control is very commonly used to obtain the low speed from which a landing is made. With the same amount of resistance the speed will vary considerably, depending upon whether the motor has a positive or negative load, but for making a landing this speed range is not too great to obtain practical results. It is the least economical method of speed control of a d-c. motor and is therefore, generally used only for obtaining the landing speeds.

By Applying a Variable Voltage to D-C. Motor Terminals. The best known system of this kind is where a separate generator is used for each motor, the generator field being changed to obtain the different motor speeds. Where the generator is properly designed the elevator motor can be operated from rest to full speed in either direction by changing the strength and the direction of the generator field. A good arrangement for the motor-generator set is to use a single motor driving two generators in order that the elevators may be shut down in pairs to eliminate the standby losses.

By Applying Several Different Voltages to the Ter- minals of a $D$-C. Motor. These different voltages are usually obtained from a motor-generator set having several different generators, each generator providing a different voltage. The transition between voltages is obtained by inserting resistance in the armature circuit. With this method of control it is necessary to reverse the armature connection to reverse its direction of rotation. One motor generator set usually supplies several elevators.

Where a storage battery is available the intermediate values of voltage may be obtained by taps taken from this battery.

The last two methods of control have been used to a limited extent. These increase the first cost of the installation but may reduce the cost of power by eliminating most of the rheostatic loss during acceleration and slowdown. This is of particular advantage in cases where the elevator motor has little speed regulation by shunt field control.

By Changing the Number of Poles of an A-C. Motor. These motors are of the induction type and may have either squirrel-cage or wound secondaries. They are usually provided for two different pole combinations; one, a large number of poles giving a low speed from which the landing is made and the other a smaller number of poles providing the regular running speed. The primary may have either two sets of windings, one for each set of poles, or a single set of windings arranged for two sets of connections. The introduction of the two-speed a-c. motor has enabled the operating speeds of a-c. elevators to be materially increased. One of the most popular combinations is a 3 to 1 ratio, although motors are now built with a 6 to 1 ratio.

By Changing the Frequency of Power Supply to an $A-C$. Motor. This method of control has been very little used up to the present. The most convenient method of obtaining the reduced frequency is to provide a small frequency changer which can be connected to the primary of the elevator motor when a low speed is desired for making a landing.

\section{DETAILS}

The elevator controller is made up of a number of unit parts, each of which performs a function in controlling the elevator. The parts usually found in a controller together with their functions are as follows:

1. A line switch for disconnecting one side of the motor from the line. This switch may be operated every time the car is moved or it may remain normally closed and be opened by a safety device or by failure of line voltage.

2. Reversing switches which change the direction of rotation of the motor and are normally used for opening and closing the motor circuit. Some of these switches operate each time the car is moved. For magnet control either two double-pole or four singlepole switches are used.

3. The accelerating device which automatically 
short-circuits the starting resistance when the motor is being brought from rest to the operating speed. A similar device may be used to limit the armature current when the field strength is changing.

4. A dynamic brake for slowing down the d-c. motor when the elevator is brought to rest. This brake consists of an electric connection between the motor terminals and a set of resistors. The switches for making these connections may form part of the reversing switches or may be separate units, the number depending upon the car speed and the type of motor.

5. A mechanical brake for making the final stop and holding the car securely at the landing. This brake is usually applied by a spring and released by a magnet.

6. Terminal stops for bringing the car gradually to rest at either limit of travel independently of the operator. Usually two different devices are used for this purpose, one of which operates normally and the other an emergency device as previously explained. The second set is generally known as overtravel limit switches.

7. Some means in the elevator car which will enable the operator to control the elevator. This may consist of a rope or a lever, a car switch or a set of push buttons depending upon the method of control.

8. A safety switch in the car for stopping in case of failure of the regular operating means.

9. A slack cable device for stopping the motor in case the car or counterweight is obstructed in its travel. A device of this kind is required only for drum machines.

10. High-speed elevators usually have a switch operated by the speed governor which automatically reduces the motor speed if it exceeds a predetermined limit.

11. Gate or door switches to prevent operating the elevator until all doors or gates are closed.

12. Every controller should provide overload protection. This may consist of fuses, but is usually a circuit breaker, or an overload relay operating in conjunction with the main line contactors.

13. Where the operating device in the car is not self-centering, low-voltage protection should be provided, to prevent the accidental starting of the elevator after failure of power until the operating mechanism has been returned to the "off" position. For a-c. elevators this device usually protects against the failure of power in any phase of the supply circuit.

14. Alternating current motors should have protection against an accidental reversal of phase which would cause them to operate in the wrong direction.

15. The higher-speed elevator controllers provide for a low-speed for making a landing. Sometimes the control provides for several operating speeds less than the maximum running speed.

16. A floor leveling device is sometimes included as part of the control. This consists of automatic means for bringing the car platform level with the landing and maintaining it in this position.

Each type of elevator requires its own special form of control. The lower-speed machines require a less complicated control than when the elevator is operated at a higher speed. Often freight elevators have different requirements from passenger machines. Considerable skill and experience is required in the designing of control equipment and selecting the necessary features. Each control should contain all of the features necessary for a successful operation, but any additional features add to the complication and may be undesirable.

\section{V-BRAKES AND OTHER SAFETY ACCESSORIES}

Brakes and other safety accessories have little to do with power application to electric elevators but they are so vitally a part of the elevator equipment that a good idea of the complete elevator plant cannot be obtained without a complete understanding of these features.

While the brake is a small part of an elevator machine it is an exceedingly important part. Because of the frequency of starts and stops it is highly essential that the car be brought to rest quickly and without shock or jar to the passengers. Also once brought to rest it is just as important that the car be maintained in its position in the hoistway while passengers are leaving and entering it. The functions of bringing the car to rest and maintaining it in a stationary position are obtained by the brakes. Elevator brakes are divided into three classes,-mechanical, dynamic and magnetic.

Mechanical Brakes. The straight mechanical brake is little used. To some extent it is still being installed on hand rope controlled freight elevators and sidewalk lifts. Most states prohibitits use on any passenger elevators because of its lack of protection to the car and occupants. As the name implies, it is simply lined brake shoes bearing against a pulley on the motor shaft. It is applied manually with the hand rope within the car, and automatically at the terminal landings by the traveling nut mechanism on the machine which has the double duty of returning the reversing switch to neutral, interrupting the motor circuit; and applying the mechanical brake. If, during operation, the voltage fails, the brake will not be automatically applied.

The mechanical brakes gives smooth results in stopping because a gradual application may easily be made by properly manipulating the control rope.

Dynamic Brakes. In the app ication of dynamic braking, advantage is taken of the ease with which a direct-current motor may be converted into a directcurrent generator. The shunt field either partially or fully energized is connected to the line, and the 
revolving armature is shunted with a resistor. Thus the motor operates as a generator and "pumps" current through the dynamic braking resistor thereby converting the mechanical energy of rotation into electrical heat. While this type of brake alone will not bring an elevator to rest, particularly if the load is overhauling, it will materially reduce the speed so that from that

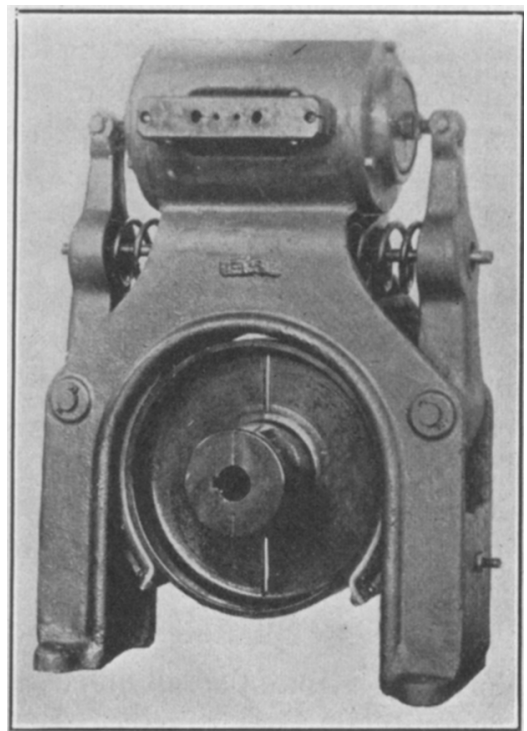

Fig. 12-D-C. Maginet-Operated Elevator Brake

speed the magnetically operated brake may easily be depended upon to bring the car to a safe and smooth stop. On the higher-speed d-c. elevators a graduated dynamic braking is furnished, which provides a braking more nearly proportional to load and speed conditions.

With alternating current, a braking effect similar to direct-current dynamic braking is sometimes furnished when a two-speed motor is used. In this case the low-speed winding is connected to the supply lines while the armature is rotating above the synchronous speed of this winding. Thus the motor acts as"a selfexcited induction generator and a powerful "dynamic" braking is obtained to bring the motor down to the synchronous speed of the low-speed winding. In this case energy is restored to the line during the braking period.

Direct-current dynamic braking is wasteful of electrical energy because the energy of rotation is lost in heat. The same applies to the mechanical brake where the energy is absorbed in the brake shoes. No effective method, economical of electrical energy, has been devised for quickly slowing down and stopping an elevator, although a direct-current motor with a wide speed range by shunt field control is economical in slowing down, as is also the two-speed alternatingcurrent motor referred to in the preceding paragraph. (See Part III.)

Magnet Brakes. The importance of the magnet brake particularly on alternating current cannot be over emphasized. See Figs. 12 and 13. The reasons for its great importance have been outlined in Part III under the subject of "The Elevator Motor."

The magnet brake consists of brake shoes, similar to those used with the mechanical brake, operated by an electromagnet. This type of brake should always be used in addition to any other, except for low-speed freight sevice, for the purpose of positively holding the car stationary at the will of the operator.

On direct current, the magnet brake has been a small problem, but on alternating current it becomes a difficult one because of difficulties in satisfactory magnet design. Various types of magnets are being used, such as single-phase long-stroke, polyphase longstroke, polyphase short-stroke and constant-stroke. The constant-stroke magnet is no more than a small motor designed to remain across the line with the rotor stalled. This magnet is sometimes called a torque motor. This type of magnet does not seal. It is difficult to keep quiet an alternating-current magnet that does seal. It is liable to slam in closure, and unless the laminated parts are perfectly surfaced and perfectly aligned it will hum after closure. A dash-pot is sometimes used for long-stroke magnets to reduce the slap in closing, and sometimes the entire magnet is immersed in oil to deaden the noise. One type of constant-air gap magnet, which is very quiet, absorbs the energy of rotation in a small auxiliary mechanical brake.

It is realized that if a mechanical brake action could be accomplished automatically in a magnet brake, smoother stopping results on alternating current could be obtained. Three manufacturers have tried the fol-

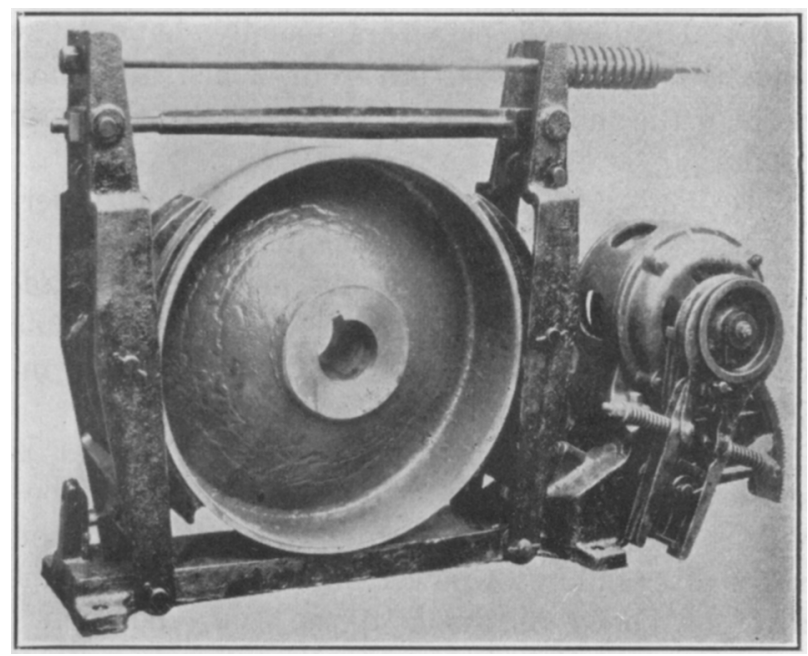

Fig. 13-A-C. Elevator Brake with Constant Air-Gap MAGNET

lowing schemes: A single magnet with the main brake spring partially counteracted by a weaker spring is used, and a dashpot is so arranged that the brake shoes are applied with partial pressure which quickly increases to maximum. The main objections to this are the use of a dashpot and the fact that the operator 
does not have any control over the weak and strong settings. Another scheme is the use of two independent magnets or complete brakes, in which case the operator has control over the weak and strong settings, giving good stopping results. The objection to this is the use of two magnets. The third method consists in the use of a single short-stroke polyphase magnet with a variable reactance in the magnet circuit proportioned

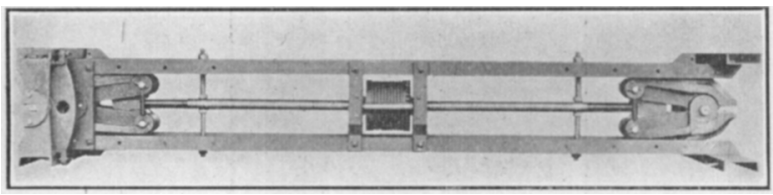

Fig. 14-Elevator Safety Guide Grips

to break the seal of the magnet but still maintain sufficient current in the brake coils to partially counteract the brake spring tension. As the car control switch is moved towards the "off" position, this reactance is decreased so the action of a mechanical brake is practically reproduced. This has worked out sufficiently well so that it is being used on elevators driven by single-speed motors and running $300 \mathrm{ft}$. per min. An objection to this method is the noise which is always present to some extent when the reactance is cut into circuit.

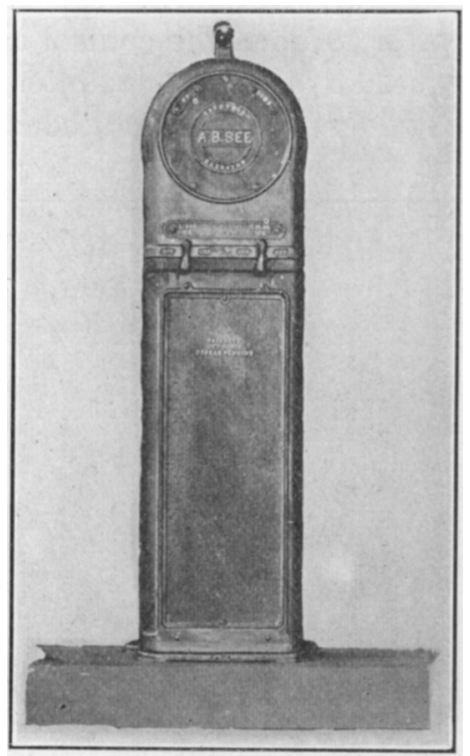

Fig. 15-Elevator Car Operating Switch

The last two types must be so wired that there will be no way for the operator to hold the weak brake condition when the car is close to the terminal landings.

As a safety measure all magnetically operated brakes are so designed that the brake is released by the magnet and applied by springs or weights, so that a failure of power will always stop the elevator.

\section{SAFETY DeviCES}

These may be classified as electrical and mechanical. The mechanical are so closely allied to the electrical that they will be briefly described. The principal safety devices are, guide grips and overspeed governor with governor switch, car-operating switch, car safety switch, terminal-limit switches, overtravel-limit switches slack-cable switch, door switches, compensating-cablesheave switch, buffers and air cushions.

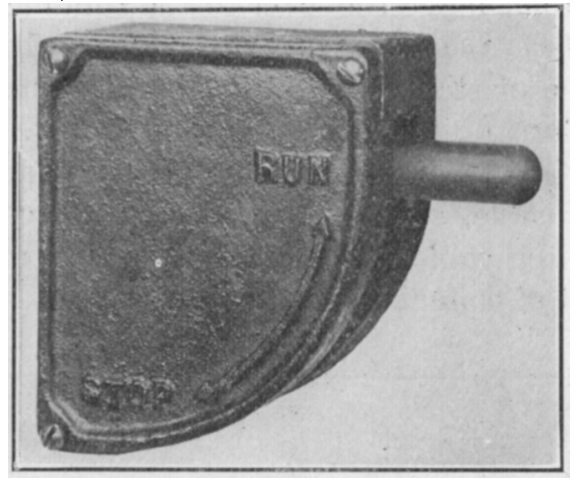

Fig. 16-Car Safety Switch

Guide Grips and Overspeed Governor. Guide grips have been made in a number of different types such as eccentric, dog, roller, and wedge, the wedge type now being almost universally adopted. See Fig. 14. The mechanism, is mounted below the car with a small winding drum which is connected to the overspeed governor by a steel cable. The holding of this cable at excessive car speeds rotates the drum so that the wedges force the grips against the guide rails and stop the car.

Usually a fly-ball type of governor is used in connection with the guide grips so arranged that the cable referred to rotates the governor shaft. The governor is arranged with a grip so that if the normal speed of

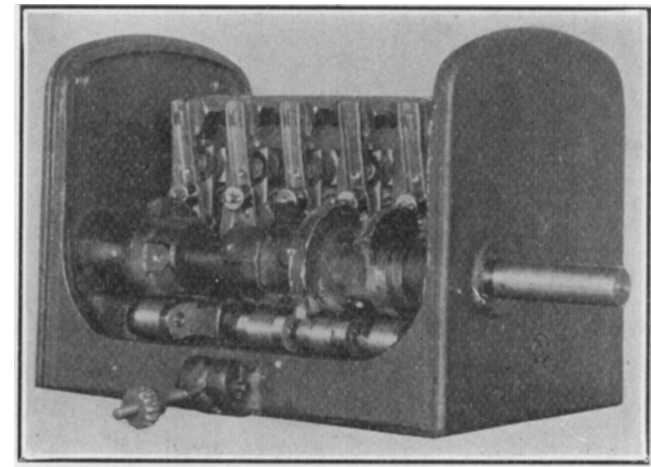

Fig. 17-Machine Limit Switch for Drum-Type Elevator

the elevator is exceeded by a fixed amount it holds the governor cable and effects the setting of the guide grips.

It is accepted practise to install a control switch on the governor, so adjusted that the switch will trip to open the control circuit and disconnect power from the motor at a speed lower than the speed at which the guide grips act. This switch prevents the guide grips from setting in case of a slight overspeeding. The switch is arranged so that it cannot be reset unless the guide grips are in the running position. 
Car-Operating Switch. The car-operating switch usually has the automatic return or self centering feature so that if the operator's hand is removed from the lever it will return to the off position. See Fig. 15. It also is ordinarily provided with a center latch so arranged that any accidental leaning against the switch will not move the lever to the running position.

Car Safety Switch. The car safety switch is for the purpose of stopping the car in emergency in case of the failure of the car operating switch. Fig. 16 . It is wired in a separate cable of opposite polarity to the car-switch cable, so that in case of grounds, etc., in the car-switch cable, the car safety switch will not be thrown out of commission.

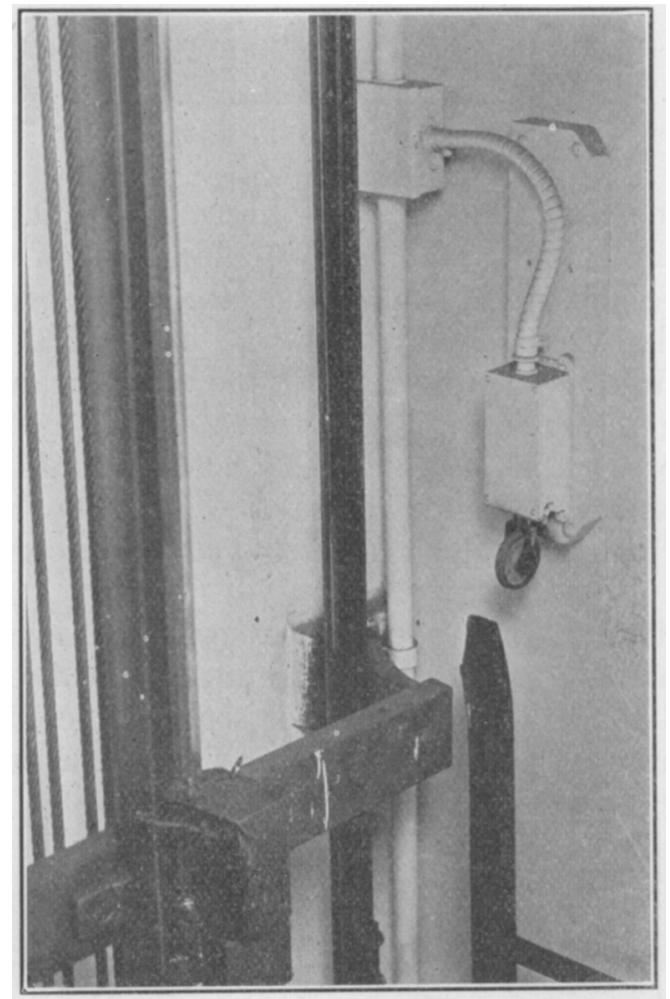

Fig. 18-Installation of Elfyator Hoistway Limit Switch

Terminal Limit Switches. These act each time the car approaches the terminal landings, and function to bring the car to rest at these landings in case the operator is careless. See Figs. 17 and 18. They may be mounted on the car and operated by cams in the hoistway or vice versa for a traction-type elevator. These may also be used on a drum-type elevator although frequently limit switches geared to the elevator machine are used instead.

Overtravel-Limit Switches. Overtravel hoistway limit switches, Fig. 18, are always mounted in the hoistway and are operated by cams on the elevator car. They are placed beyond the normal range of car travel, and function to stop the car in case of the failure of the regular terminal stop limits. It is very desirable and the usual practise to arrange the connections to these limits so that the car cannot be backed out of them by manipulating the car switch. This gives an added safety feature as it requires the operator to call the attention of an electrician or someone connected with the maintenance department to the fact that the car ran into the overtravel limits, and have the cause of this overrunning corrected.

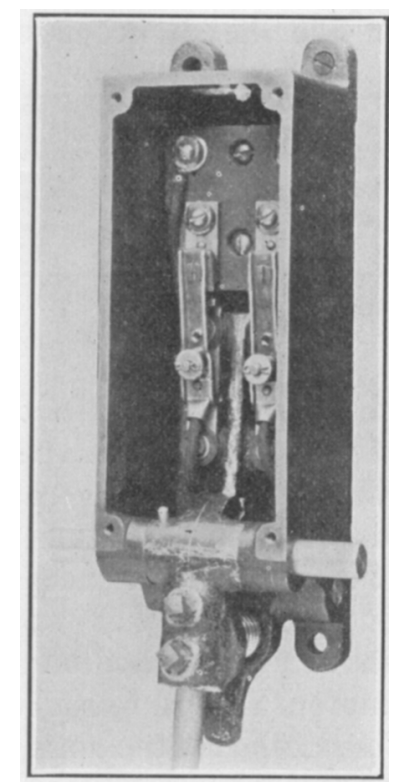

Fig. 19-Slack-Cable Su Itch

Slack-Cable Switch. Ordinarily this is used on a drum-type elevator to open the control circuit in case of slack cable caused by the car or counter-weight being caught in the guides. It is operated automatically

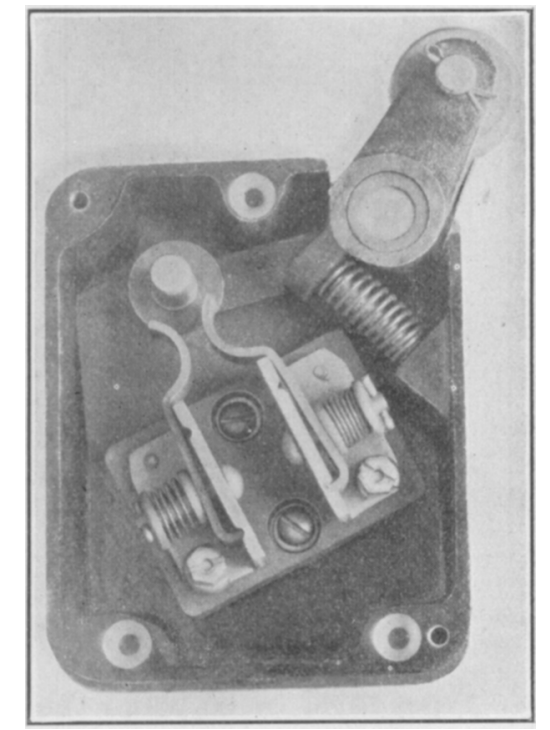

Fig. 20-Elevator Door Safety Switch

when the cables slacken. See Fig. 19. It is sometimes mounted on top of an elevator car of high travel traction elevators where the cable weight is so great that the machine may not entirely lose traction in case of the bottoming of the car.

Door Safety Switches. These, Fig. 20, in combination with door locks, prevent the car from operating 
unless all doors are closed and locked. The design requirements of these devices are in many cases regulated by safety codes. There are numerous types manufactured and many have little value, so that door locks and switches should be investigated before installing. Some combinations lock the car-operating switch in neutral while the door is open. Others interrupt the car-control circuit when the door is open. Because the large majority of elevator accidents are

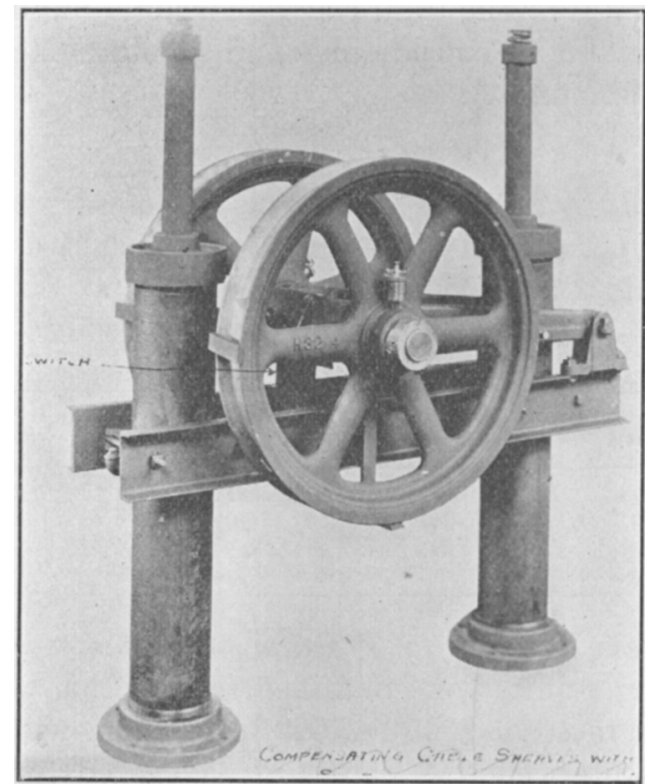

Fig. 21-Elevator Compensating Cable Sheaves with SwITCH

due to not using suitable door interlocks, it is advisable to use them even though it decreases the service of the elevator to some extent. (See Part I.)

Compensating Cable Switch. This is connected so that it is opened by the lowering or raising of the compensating cable sheaves in the pit. See Fig. 21. The switch interrupts the control circuit and stops the car should the sheaves lower to any appreciable extent due to cable stretch. Also, in case of the car or its counterweight being caught in the guides, the compensating cable sheave will raise and operate the switch to cut off power.

Buffersand AirCushions. A buffer is always required under the car. For lower speeds a spring alone is used, but for higher speeds a combination of oil dashpot and spring is used, Fig. 22. These must provide a retarding effect so that maximum retardation will not exceed 64.4 feet per second per second.

At one time an air cushion was required for certain service in certain localities. This consists of a hoistway practically air tight at the lower end for a certain percentage of the total height. This involved very expensive enclosure construction and while effective in retarding the motion of a falling car it is understood the air cushion has been practically abandoned as unnecessary to safety. Another disadvantage of this scheme is the additional power required to move the car due to air friction.

\section{Protective Devices}

Besides the various forms of brakes and safety devices above described most elevators are protected against abuse by the following apparatus:

Main Line Service Switch and Fuses. These are mounted in an accessible location in the elevator machine room and are usually enclosed in a metal cabinet, preferably with an externally operated knife switch, and with a mechanical interlock making it necessary to open the knife switch before the cover can be opened to inspect or replace fuses.

Circuit Breakers and Overload Relays. Circuitbreaker protection of individual elevator motors is not very often used inasmuch as the National Electrical Code requires fuse protection of elevator motors even when circuit breakers are used.

Frequently, however, in addition to the service fuses, overload relays are used in order to secure protection against overloading of the elevator itself. The overload relays are set below the fuse rating so as to prevent the blowing of fuses. The overload relays are sometimes made to reset automatically with the

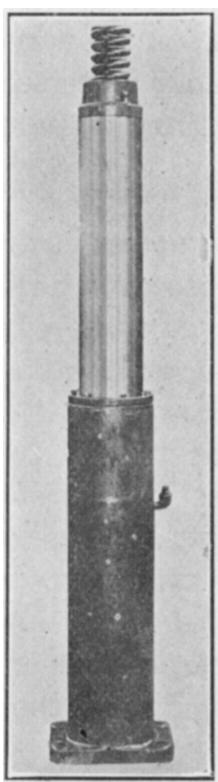

Fig. 22-Elevator Oil Buffer

return of the operating switch handle to neutral, so that after an overload it is unnecessary to go to the elevator machine room to again place the elevator in operating condition.

Overspeed Slow-down Relay. Some builders include in their electrical equipment a voltage relay so connected that an overspeeding of the elevator in either direction will cause the relay to act and thus automatically retard the speed. This relay is set to act at a speed below that at which the overspeed governor is set.

Phase-Failure Protective Relay. All alternating- 
current elevator installations on which the elevator motor may be continuously connected to the lines, such as hand-rope and push-button controlled elevators, include some form of phase-failure protection. Otherwise, upon the failure of a phase, the motor may be stalled on the single-phase condition, and burn out. The protective relay is usually a polyphase, shuntwound relay with a control-circuit contact to maintain the control circuit of the elevator controller so long as the phases are all alive. The failure of any phase causes the relay to open the controller circuit and thus disconnect the motor from the supply lines.

Phase-Reversal Protective Relay. Many State electrical codes now require a phase-reversal protective relay on all polyphase a-c. installations. Frequently the phase-failure and phase-reversal relays are combined in one device. The reversal of phases immediately opens the controller circuit and prevents the elevator motor being connected to the lines until the relation of the phases is corrected.

\section{VI-POWER CONSUMPTION}

Anyone connected with building or industrial plant operation is interested in the power consumed by electric elevators. The architect and engineer are interested. The building owner is interested. From a conservation standpoint, everyone interested in the country's welfare is anxious to see the most economical use of electric power for all purposes.

\section{Determining FACTORS}

There are so many factors entering into this problem that it is impossible to give any accurate power consumption figures for any one type of elevator with a given capacity and running at a given speed, with a specified load on the car and with a specified number of stops per mile of car travel.

The operator himself is one of the variables. Some elevator operators run their cars to good advantage from a power economy standpoint, but many others are most careless in the way they operate.

Besides the operator's effect on economy other variables are inertia (including the weights of the car, counterweights, lifting ropes, balancing ropes, or chains, all moving pa:ts of the machine etc.), rate of acceleration, and design and construction of all parts entering into the complete elevator. To show the importance of these factors, one company may design an elevator for a capacity of five tons that will have in its make-up approximately one half the material that another company may deem advisable for the same capacity and speed. When it comes to power consumption the lighter weight apparatus will naturally win out, even though it may not last long, due to its light construction. Therefore tests showing power consumption are naturally subject to all the variations that are inherent in elevator manufacture which is still somewhat lacking in standardization.
Regardless of all these variables it is of course possible to quote actual test figures for various types of elevators so that a general idea of the power consumed may be obtained.

The power consumption of electric elevators ranges from two to three $\mathrm{kw}$-hr. per car-mile up to ten or more depending upon the variables mentioned above, but depending mostly upon loads, speeds, rate of acceleration, and number of stops per car-mile. Elevators make as many as 25 miles of travel per day so that even in a day's time the total energy consumption in a large office building is considerable and should be kept down to a minimum.

\section{Results of Tests}

Geared, Drum-Type Elevators. An average of several drum-type, geared elevators, with capacities between 2000 and 2500 pounds, at 350 to $400 \mathrm{ft}$. per min. regular service indicates the following results:

\begin{tabular}{c|c|c|c}
\hline Capacity & Speed & $\begin{array}{c}\text { Total miles } \\
\text { per day }\end{array}$ & $\begin{array}{c}\text { Kw-hr. per } \\
\text { car-mile }\end{array}$ \\
\hline 2000 & 350 & 11.25 & 3.98 \\
2500 & 400 & 10.90 & 4.35 \\
2000 & 400 & 15.20 & 3.58 \\
Average & & 12.45 & 3.97 \\
\hline
\end{tabular}

Gearless Full Wrap Traction, 1 to 1 Roping. The following results were obtained from actual test of an elevator rated at $2500 \mathrm{lb}$., $500 \mathrm{ft}$. per min. with $800 \mathrm{lb}$. over-counterweight. Values are averaged for up and

\begin{tabular}{c|c|c}
\hline & \multicolumn{2}{|c}{ Kw. hours per car-mile } \\
\cline { 2 - 3 } Stops per car-mile & Balanced & Full load \\
\hline 0 & 1.20 & 1.82 \\
50 & 2.22 & 3.39 \\
75 & 2.90 & 4.07 \\
100 & 3.50 & 4.80 \\
125 & 4.10 & 5.46 \\
150 & 4.28 & 5.93 \\
200 & 5.12 & 7.10 \\
250 & 5.81 & 9.07 \\
300 & 6.50 & 9.20 \\
400 & 7.90 & 11.50 \\
\end{tabular}

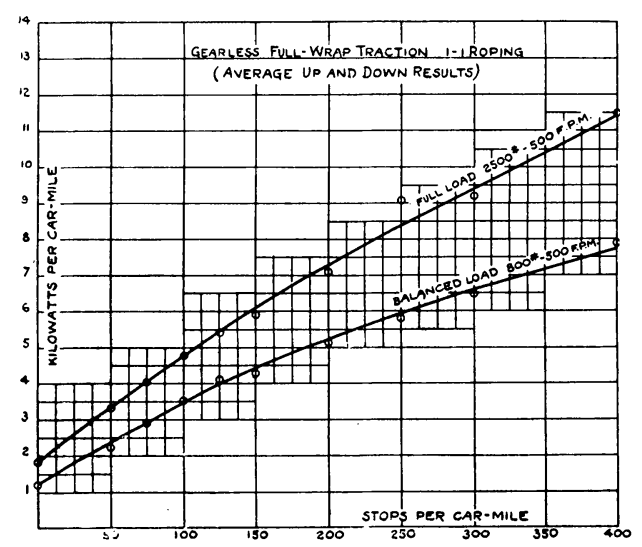

Fig. 23-Results of Test of Gearless Full-Wrap Traction Elevator, 1-1 Roping

Values averaged for up and down operation. 
down operation. The results are plotted in Fig. 23. The curves clearly show the variation in power consumption with load changes and with variation in the number of stops per car mile.

Another set of tests on a gearless 1 to 1 machine rated at $2500 \mathrm{lb}$., $500 \mathrm{ft}$. per min., in a ten-story office building gave the following results. These are up and down averages. The car weighed $3900 \mathrm{lb}$. and there was $1060 \mathrm{lb}$. over-counterweight.

\begin{tabular}{|c|c|c|c|c|c|c|c|}
\hline 52 Stops per car-mile & & & & & & & \\
\hline Load in lb............ & Operator & 666 & 1060 & 1360 & 2010 & 2360 & 2660 \\
\hline $\begin{array}{c}\text { Kw-hr. per car-mile. . . . . } \\
104 \text { Stops per car-mile }\end{array}$ & 2.35 & 2.08 & 1.95 & 1.87 & 2.15 & 2.50 & 3.22 \\
\hline 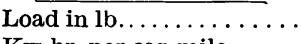 & Operator & 666 & 1060 & . & 2010 & $\cdots$ & 2660 \\
\hline $\begin{array}{c}\text { Kw-hr. per car-mile. ..... } \\
208 \text { Stops per car-mile }\end{array}$ & 3.09 & 2.86 & 2.52 & . & 2.92 & . & 3.86 \\
\hline Load in $\mathrm{lb} \ldots \ldots \ldots \ldots$ & Operator & 666 & 1060 & . & 2010 & . & . \\
\hline $\begin{array}{c}\mathrm{Kw} \text {-hr. per car-mile ..... } \\
\mathbf{4 1 6} \text { Stops per car-mile }\end{array}$ & 4.91 & 4.19 & 3.98 & . & 4.25 & . & . \\
\hline Load in lb............. & Operator & 666 & 1060 & . & 2010 & . & . \\
\hline Kw-hr. per car-mile. ..... & 7.29 & 6.75 & 6.7 & . & 7.43 & . & ... \\
\hline
\end{tabular}

A test was made in a fifteen story building. The elevator was rated at $2750 \mathrm{lb}$. at $500 \mathrm{ft}$. per min. The regular service test with approximately 100 stops per car mile gave an energy consumption of between 3.32 and $4.73 \mathrm{kw}-\mathrm{hr}$. per car-mile.

The effect of increased number of stops is shown in the following results obtained from a test in a 22-story office building:

Empty - Stopping at every floor........ 6.4 kw-hr. per car-mile Full Load — Stopping at every floor........10.4 " " " " " $2 / 3$ Load - Stopping at top and bottom only. . 2.4 " " " " "

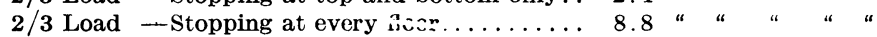

A 22 -floor $600 \mathrm{ft}$. per min. elevator with express service to the tenth floor and local service from the tenth to the twenty-second floor, traveling an average of 22 miles a day consumed $3.5 \mathrm{kw}$-hr. per car-mile. Local elevators in the same building operating at $400 \mathrm{ft}$. per min. traveled nine miles per day and consumed an average of $4 \mathrm{kw}$-hr. per car-mile each.

Gearless Full-Wrap Traction Elevator 2 to 1 Roping. The only tests available for publication are shown in the following table. The elevator was rated at 3000 lb., $500 \mathrm{ft}$. per min., $1175 \mathrm{lb}$. over-counter-weight was used. Average up and down results are given:

\begin{tabular}{c|c|c}
\hline & \multicolumn{2}{|c}{ Kw-hr. per car-mile } \\
\cline { 2 - 3 } Stops per car-mile & Balanced & Full Load \\
\hline 0 & 2.00 & 3.80 \\
50 & 2.90 & 4.60 \\
75 & 3.40 & 5.40 \\
100 & 3.90 & 6.00 \\
125 & 4.33 & 6.95 \\
150 & 4.81 & 7.80 \\
200 & 5.80 & 8.71 \\
250 & 6.78 & 10.40 \\
300 & 7.68 & 11.10 \\
400 & 9.06 & 15.20 \\
\hline
\end{tabular}

Geared Half-Wrap Traction Elevator. A test was made on several elevators rated at $2500 \mathrm{lb}$, $600 \mathrm{ft}$. per min., with the following average up and down results:

\begin{tabular}{c|c|c}
\hline Stops per car-mile & Load in lb. & Kw-hr. per car-mile \\
\hline 16 & 1100 & 2.06 \\
80 & “ & 4.20 \\
96 & 4 & 4.70 \\
16 & 2500 & 2.40 \\
80 & $“$ & 4.80 \\
96 & $“$ & 5.20 \\
\hline
\end{tabular}

An elevator running $400 \mathrm{ft}$. per min. serving an 18-story building and traveling an average of 21.8 miles per day showed a regular service consumption of $3.28 \mathrm{kw}$-hr. per car-mile.

Another at the same speed in a 13-story building and traveling 19 miles a day consumed $3.88 \mathrm{kw}-\mathrm{hr}$. per car-mile.

The average of a lot of $400 \mathrm{ft}$. per min. elevators was $3.8 \mathrm{kw}-\mathrm{hr}$. per car-mile.

The following test results were obtained with an elevator having a capacity of $2250 \mathrm{lb}$. at $500 \mathrm{ft}$. per min. The over-counterweight was $580 \mathrm{lb}$. In this case the motor had a 3 to 1 speed variation by shunt field control. Had there been less or no control by shunt field variation the power consumption values would have been considerably higher. (See Part III.)

\begin{tabular}{c|c|c}
\hline & \multicolumn{2}{|c}{ Kw-hr. per car-mile } \\
\cline { 2 - 2 } Stops per car-mile & Balanced & Full Load \\
\hline 0 & 1.50 & 2.05 \\
50 & 2.10 & 3.00 \\
75 & 2.50 & 3.43 \\
100 & 2.92 & 3.90 \\
125 & 3.30 & 4.46 \\
150 & 3.57 & 4.90 \\
200 & 4.23 & 5.91 \\
250 & 5.30 & 6.70 \\
300 & 5.90 & 7.55 \\
400 & 6.95 & 8.50 \\
\hline
\end{tabular}

Lack of proper maintenance will also increase the power consumed. It is evident that all moving parts such as the machine itself, sheaves, guides, etc. must be properly lubricated at regular intervals in order to insure the most economical results. Also if the brakes are not properly adjusted the operators will find difficulty in making accurate stops without inching and the resultant loss in power.

\section{CONCLUSION}

While the above test figures are of interest they actually are of little comparative value on account of the many variables indicated under "Determining Factors." Some years ago the Cincinnati Gas \& Electric Company made some operating cost tests on a great many elevators in its district. The averages of all these tests are given as follows: 


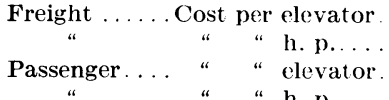

$\$ 8.00$ per month

1.09 per month

14.64 per month

1.26 per month

These are, of course, costs for power only, and would not apply with present-day power costs.

Attention is called to the fact that the big determining factor in the cost of elevator operation lies in the number of starts and stops and not in the load carried by the car.

\section{WAYS IN WHICH OPERATION AND MAINTENANCE AFFECT Power Consumption}

It has already been mentioned that the operator himself is one of the important factors determining the power consumption of electric elevators. It is interesting to note how this factor affects the results.

If an operator is so expert that he slows down the car as nearly as possible to the landing at which he is to stop and if he stops the car accurately with the landing without "inching" he reduces the current used in slowing down or running at low speed and reduces the number of starts and stops by eliminating the inching operation so frequently used by unskilled operators. Besides this he improves the service of the elevator which point is of vital consideration.

Evidently from the manner in which many elevators are run little attention is paid to this important factor in elevator economy. If building owners would realize the importance of this point it would be possible by careful instruction and competition between operators to materially cut down the power consumption on many installations.

Towa:- Is this end a watt-hour meter might be installed on each elevator. Also car-mile recorders and counters for registering the number of stops could be added. In this way accurate data on the performance of each elevator could be obtained. If an operator is assigned to a particular machine a bonus might be paid to the operator who showed unusual saving in power consumption due to skilful operation. In a large building this would set up a rivalry between operators and might be very beneficial from the standpoint of the power consumed.

\section{Bibliography}

"Elevator Safeties," Charles R. Pratt. A. S. M. E. Paper No. 940 dated 1902.

"Passenger Elevators," 'Thos. E. Brown. A. S. C. E. Paper No. 22 dated 1904.

"Operating Conditions of Passenger Elevators," Reginald P.

Bolton. A. S. M. E. Paper No. 1300 dated 1910.

"A High Speed Elevator," Chas R. Pratt. A. S. M. E. Paper No. 1161 dated 1907.

"Modern Electric Elevators and Elevator Problems," David

L. Lindquist. A. S. M. E. Paper No. 1504 dated 1915.

"Elevator Service," Reginald P. Bolton. Paper dated 1908. 5275 th Avenue, New York City.

"Hydraulic Elevators," Wm. Baxter, Jr. Paper dated 1910.

"Elevators in Modern Office Buildings," Reginald P. Bolton. 5275 th Avenue, New York City.

"Elevators (Development \& Design)," John H. Jollings. Paper dated 1915.
"Elevators (Hydraulic \& Electric)," (Containing handbook descriptions and illustrations). Calvin Frank Swingle.

"Elevators (Care and Operation)". Aetna Life Insurance Co.

"Report on Field Survey of Elevator Interlocks and Contacts", Bureau of Standards, Washington, D. C.

"Elevators \& Steam Engines (Care \& Operation)". International Correspondence Schools. Published by International Text Book Co.

"Elevator Control," F. E. Barnum. A. I. E. E. Paper dated 1911.

\section{CAPACITY EFFECTS IN INDUCTANCE COILS}

A coil of wire wound in any of the familiar forms called "inductance coils" behaves in an electric circuit primarily as an inductance. The potentials of the different parts of the coil are, however, different from each other and from the potential of the ground. For this reason, the coil also behaves to a certain extent as an electric condenser, or rather a system of condensers.

On account of the importance in radio communication of capacity effects in inductance coils, careful studies of these effects, both theoretical and experimental, have been made at the Bureau of Standards, Washington, D. C. An interesting result which has been found is that one effect seems to depend primarily on the capacity of the coil to ground. This effect is observed when two condensers in series are connected across the terminals of the inductance coil, and the common terminal of the two condensers is grounded. If the inductance coil possesses capacity to ground, the familiar criterion for resonance in the system, computed from the known value of the capacities of the two condensers, will not apply.

If both condensers are variable, and the system is adjusted for resonance by successively assigning arbitrary values for the setting of one condenser, and then tuning with the other condenser, it would be expected from elementary considerations, neglecting the effects of distributed capacity, that the successive resonance values of the capacity of the two condensers in series, determined as the product of their capacities divided by their sum would be constant. On account of the distributed capacities, this simple relation does not hold. It is found, however, that under the conditions above mentioned, with the common terminal grounded, the capacity of the two condensers in series determined as the product of their capacities divided by their sum, is linearly related to the reciprocal of the sum of their capacities. This relation has been verified both mathematically and experimentally.

The results of both the mathematical and experimental investigation of this particular phase of the problem of capacity effects in inductance coils are given in a publication of the Bureau of Standards, Scientific paper No. 427,"Some Effects of the Distributed Capacity Between Inductance Coils and the Ground." 